\title{
An audit of total parenteral nutrition in Altnagelvin Hospital
}

\author{
D. M. Comer, F. McAuley and G. B. Turner \\ Department of gastroenterology, Altnagelvin Area Hospital, Londonderry, $N$ Ireland
}

The National Institute of Health and Clinical Excellence (NICE) and the British Association for Parenteral and Enteral Nutrition (BAPEN) have published guidelines for the indications, duration, route of administration and potential complications of parenteral nutrition (PN) for patients who have an inaccessible or non-functioning intestine ${ }^{(1,2)}$. Furthermore, a large study using the Northern Nutrition Network (NNN) collected data in order to establish a national baseline against which individual hospitals could audit PN practice in the various facets of PN delivery for comparative purposes ${ }^{(3)}$.

Information was gathered by case-note retrieval and the use of a paper-based collection tool for forty-eight patients who had received PN over a 6-month period. Data for all forty-eight patients included patient demographics, indications, duration, venous access used, complications, number returning to enteral feeding and mortality.

Data on forty-eight patient PN episodes were recorded totalling 402 patient days. The median age of the patients was 59 years (NNN: 67 years). Of these, forty-two $(88 \%)$ were regarded to have a clear indication for PN using NICE guidelines (NNN: $82 \%)$. The average duration of PN was $8 \mathrm{~d}$ (range 4-12) (NNN: average duration $7 \mathrm{~d}$ (range 1-93)). Five (10\%) patients developed a complication due to PN (NNN: $16 \%)$. Forty-two $(88 \%)$ of the total PN episodes were initiated in intensive care. Biochemical and haematological monitoring while on PN was thorough. Forty-eight (100\%) of patients received PN via a central line (NNN: $81 \%)$. Forty-four (92\%) returned to full enteral feeding (NNN: $61 \%$ ). No patient received PN for $4 \mathrm{~d}$ or less. Four patients $(8 \%)$ died while receiving PN (for unrelated reasons).

The delivery of PN is in accordance with current guidelines and above an established national standard.

1. NICE (2006) Nutrition Support in Adults: Oral Supplements, Enteral Tube Feeding and Parenteral Nutrition. 2006; NICE. Available at: http:// www.nice.org.uk.

2. Pennington, CR, Fawcett, H, McWhirter, J, Sizwer, T \& Whitney, S (1996) Current perspectives on parenteral nutrition in adults. A report by a working party of the British Association for Parenteral and Enteral Nutrition; BAPEN.

3. Hearnshaw SA, Thompson NP and the Northern Nutrition Network (2007). Use of parenteral nutrition in hospitals in the North of England. J Hum Nutr Diet. 20 (1):14-23; quiz 24-6. 